\title{
WizePairZ: a novel algorithm to identify, encode, and exploit matched molecular pairs with unspecified cores in medicinal chemistry
}

\author{
Dan J Warner ${ }^{1}$, Stephen A St-Gallay ${ }^{1 *}$, Edward J Griffen ${ }^{2}$ \\ From 6th German Conference on Chemoinformatics, GCC 2010 \\ Goslar, Germany. 7-9 November 2010
}

\begin{abstract}
An algorithm to automatically identify and extract matched molecular pairs from a collection of compounds has been developed, allowing the learning associated with each molecular transformation to be readily exploited in drug discovery projects. Here, we present the application to an example data set of 11 histone deacetylase inhibitors. The matched pairs were identified, and corresponding differences in activity and lipophilicity were recorded. These property differences were associated with the chemical transformations encoded in the SMIRKS reaction notation. The transformations identified a subseries with the optimal balance of these two parameters. Enumeration of a virtual library of compounds using the extracted transformations identified two additional compounds initially excluded from the analysis with an accurate estimation of their biological activity. We describe how the WizePairZ system can be used to archive and apply medicinal chemistry knowledge from one drug discovery project to another as well as identify common bioisosteres.
\end{abstract}

Author details

${ }^{1}$ AstraZeneca, Loughborough, UK. ${ }^{2}$ AstraZeneca, Alderly Park, UK.

Published: 19 April 2011

doi:10.1186/1758-2946-3-S1-09

Cite this article as: Warner et al: WizePairZ: a novel algorithm to

identify, encode, and exploit matched molecular pairs with unspecified

cores in medicinal chemistry. Journal of Cheminformatics 2011 3(Suppl 1): O9.

\footnotetext{
* Correspondence: steve.st-gallay@astrazeneca.com

${ }^{1}$ AstraZeneca, Loughborough, UK

Full list of author information is available at the end of the article
}

\section{Publish with ChemistryCentral and every scientist can read your work free of charge \\ "Open access provides opportunities to our colleagues in other parts of the globe, by allowing anyone to view the content free of charge." \\ W. Jeffery Hurst, The Hershey Company. \\ - available free of charge to the entire scientific community \\ - peer reviewed and published immediately upon acceptance \\ - cited in PubMed and archived on PubMed Central \\ - yours - you keep the copyright \\ Submit your manuscript here: \\ http://www.chemistrycentral.com/manuscript/

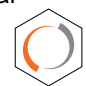 \\ Chemistry Central}

